\title{
THE EFFECT OF BILINGUALISM ON EFL ELEMENTARY LEARNERS' LISTENING COMPREHENSION: THE CASE OF AZERI- TURKISH VS. PERSIAN STUDENTS
}

\author{
Ali ARABMOFRAD * \\ iD : https://orcid.org/0000-0003-0191-2717 \\ Golestan University, Iran
}

\author{
Majid SAEIDI \\ iD : https://orcid.org/0000-0002-6116-1698 \\ Islamic Azad University of Gorgan, Iran \\ Mohammad MOTAMEDI \\ iD : https://orcid.org/0000-0002-5099-4723 \\ Golestan University, Iran
}

(C) The Author(s) 2020

\begin{tabular}{|c|c|}
\hline ABSTRACT & $\overline{\text { ARTICLE INFO }}$ \\
\hline $\begin{array}{l}\text { Since the phenomenon of bilingualism is gradually increasing in the world, the } \\
\text { theory-driven and practically oriented investigation on bilingualism have increased } \\
\text { recently. However, a few studies have been conducted on the effect of bilingualism } \\
\text { on language learning in the multilingual and multicultural context of Iran. Therefore, } \\
\text { the main aim of the present study is to examine the effect of bilingualism on Iranian } \\
\text { EFL learners' listening comprehension in the case of Azeri-Turkish vs. Persian } \\
\text { students. The study employed a quasi-experimental design over } 8 \text { weeks with } 44 \\
\text { female students assigned to one of the two experimental groups. To select bilingual } \\
\text { and monolingual groups, a biographical questionnaire was used. Then, Nelson } \\
\text { elementary proficiency test was administered to ensure the homogeneity of the } \\
\text { students. To fulfill the purpose of the study, } 15 \text { bilingual (Azeri-Persian) elementary } \\
\text { students in Fazilat high school in Ramian and } 29 \text { monolingual (Persian) elementary } \\
\text { students in Sama high school in Azadshahr were selected to participate in the } \\
\text { present study. Each group received } 16 \text { sessions of treatment in listening skill. Then, } \\
\text { the two groups' performance was compared on pretest and posttest consisting of a } \\
\text { multiple-choice and matching listening comprehension test. The results indicated } \\
\text { that there was no significant difference between the bilingual and monolingual } \\
\text { groups regarding their performance on listening comprehension, that is, } \\
\text { bilingualism did not affect listening comprehension. }\end{array}$ & $\begin{array}{l}\text { ARTICLE HISTOI } \\
\text { Received: } \\
5 \text { April, } 2020 \\
\text { Accepted: } \\
\text { 13 August, } 2020 \\
\text { Published: } \\
\text { 30 October, } 2020 \\
\text { Available online: } \\
\text { 30 October, } 2020\end{array}$ \\
\hline
\end{tabular}




\section{Introduction}

Bilingualism is a very general phenomenon all around the world and bilingual families exist very often in every society nowadays (Saunders, 1988). It is estimated that 5,000 different languages are spoken in around the world among 200 countries; therefore, communication among different citizens of different countries definitely leads to bilingualism or multilingualism and is an important fact all around the world nowadays. In fact, two-third of children all around the world born and grow up in bilingual conditions (Crystal, as cited in Bhatia \& Ritchie, 2006). In this regard, Bialystok (2003) cited that languages, neighborhood, educational system, and the language which is spoken outside the home are the important issues in bilingualism. Since being in contact with some aspects of other languages is unavoidable and no language can protect itself from changing and entering new words and phrases from other languages, it is probably impossible for adults to be purely monolingual (Bialystok, 2003).

In addition, bilingualism has different degrees and can be evaluated in the four skills of listening, speaking, reading and writing. Listening is one of the most primary factors to communicate. It is the act of decoding in which the listener decodes the speech as an auditory input in which the auditory input transforms into a mental reconstruction of the listener. Understanding the speaker's speech to adequate communication is important for a listener (Hulstijn \& Heuven, 2003). A lot of studies have been conducted on the effect of bilingualism on learners' learning (e. g., Gorjian \& Mahmoudi, 2012; Lambert, 1997; Lee \& Kim, 2011; Samadi \& Maghsoudi, 2013; Yamchi and Kumar, 2016). However, to the best of researcher's knowledge, no study has been conducted on the effect of bilingualism on EFL learners' listening comprehension among Iranian Azeri-Turkish and Persian students that is investigated in the present study.

According to the previous studies conducted on the role or the effect of bilingualism on language learning such as writing, reading comprehension, and pronunciation, bilingualism affects language learning (e. g., Bialystok \& Chang, 2005; Gorjian \& Mahmoudi, 2012; Merrikhi, 2012; Samadi \& Maghsoudi, 2013). Even though a lot of studies have been conducted on bilingualism and listening comprehension, in Iranian context just Gorjian and Mahmoudi (2012) conducted a study on the role of bilingualism and monolingualism in listening comprehension of learning English as a foreign language among Arab-Persian bilinguals. Yamchi and Kumar (2016) also compared Iranian monolingual and bilingual university students' listening comprehension in terms of watching English movie with Latinized Persian subtitles. However, it seems that no study has been conducted on 
how bilingualism affects EFL listening skill in Azeri Turkish-Persian junior high school students in Iran. Therefore, the purpose of this quasi-experimental study is to test the hypothesis about whether there is any significant effect of bilingualism between bilinguals (Azeri Turkish-Persian) and monolinguals (Persian) on listening comprehension. Therefore, in this study, an attempt was made to answer the following question:

Does bilingualism have any significant effect on Iranian EFL elementary learners' listening comprehension?

\section{Bilingualism}

Language is exquisitely tied to memory and to the functions that encode and store information as well as to those assisting us in retrieving information (Heredia \& Altarriba, 2013). According to Edwards' study (as cited in Bhatia \& Ritchie, 2006), there seems to be nobody in the world who does not know at least some words in other languages except their mother tongue. Guagnano (2009) pointed out that although the concept of being bilingual often seems simple and non-ambiguous, it covers a vast classification of concepts each of which has a different emphasis. Bilingualism refers to a linguistic community in which two languages contact each other and so two codes can be used in the same interaction (Hamers \& Blanc, 2004). According to the Longman dictionary of language teaching and applied linguistics a bilingual person is defined as the one who uses at least two languages with some degree of proficiency (Richards \& Schmidt, 2010).

These definitions, which are from a variety of native-like knowledge in two languages to a very small amount of proficiency in a second language, propose some theoretical and methodological problems. On the one hand, they lack the quality of being very exact and correct and operational (Hamers \& Blanc, 2004). For instance, Mohanty (as cited in Hamers \& Blanc, 2004) limited bilingualism to the social-communicative aspect and stated that bilingual persons or communities are those who can visit the needs of communication and the society in their usual performing in two or more languages in their conversation with other people.

For the bilingual person, the linguistic aspects of encoding and retrieval can occur in one or two languages (Schroeder \& Marian, 2012) and the bilingual experience can positively and negatively affect various cognitive and linguistic processes, which, in turn, leads bilinguals to show enhanced memory in certain situations and impaired memory in other situations (Heredia \& Altarriba, 2013). 
Moreover, languages, neighborhood, educational system, and the language which is spoken outside the home are the important issues in bilingualism. There are some factors such as the age of acquisition, language transfer, cognitive and brain development, motivation, educational environments, and language exposure that make bilingualism and second language acquisition more complicated and extremely interesting than the first language acquisition (Ellis, 2005).

Age, as a moderating variable, has strong effects on the equality of first language acquisition with second language acquisition in phonology, lexicon, syntax, morphology, and pragmatics. Furthermore, these effects are different in one field from another (Ellis, 2005). On a very general consideration of bilingualism, age has a negative correlation between acquisition and level of achievement in the second language (L2). What is most rational is that there is a limited period to develop the second language acquisition to make native-like achievements and after that it is impossible. Despite this is an acceptable hypothesis because critical periods are seen in the process of growth of many groups, there is not much general agreement on relation to the critical period hypothesis (CPH) when it affects second language acquisition.

Nevertheless, Pavlenko (2005) stated bilingualism can be very useful and beneficial for improving linguistic knowledge of speakers and offering them understanding which is important for changeable and critical thinking. Further, they have greater cognitive flexibility (Paradis, 2005).

Evaluating the degree of bilingualism is a very eminent problem even for reasons other than research aims. Guagnano (2009) provided that to collect information about the age of acquisition and the language the bilinguals use in everyday life, the reported measures such as questionnaires and interviews are prosperous. Guagnano (2009) stated that to evaluate the linguistic proficiency objectively, there is a way to get this through observed measures. According to Guagnano (2009), observed measures involve both tests of competence in the first and second languages.

\section{Listening Comprehension}

Listening comprehension is one of the most complex skills in language learning (Oxford, 1993), especially in the case of an unidirectional listening mode where the listener is unable to interact with the speaker as in the case of watching a movie to comprehend its content (Graham, 2006 Even though listening was a skill that had a common role (and still it has) in the language acquisition process, it 
began to be taught as a separate skill of language from 1970 (Rost, as cited in Hulstijn \& Heuven, 2003).). Since 1990, the listening skill has been considered as an important factor in foreign language teaching andpeech understanding was the problem that was increasingly focused when anthropologists began to explain the oral languages of the world. (Bloomfield, as cited in Hulstijn \& Heuven, 2003).

Moreover, listening is a very difficult skill to be mastered for students who have to understand a foreign language. One reason is that we learn the foreign language in the classroom in which we see words and sentences in a good organization on the board and when the teacher pronounces them slowly and clearly, we have enough time to recognize them. Another difficulty is that many teachers believe in a high-standard comprehension of how English is pronounced. In addition, different listeners take different aspects of a massage (Hulstijn \& Heuven, 2003).

Additionally, Davis and Osborn (2003) point out that the input which students receive has to be processed. It is especially very difficult and complex activity to lower and beginner learners. The lower-proficiency students cannot remember what is said and pre-listening activity can be useful for them. During the 1940s and 1950s, EFL teaching presumed that comprehension is a bottom-up model in which listeners start with recognizing phonetic sounds, phonemes, morphological structure and so on, finally to get a word. Then listeners do the same process to the next word, phrase, and sentence and so interpret the sentence semantically. Recently, it is proved that the bottom-up model is an insufficient one to complete comprehension. Listeners need some background to comprehend a text completely. A very important process of comprehension is the top-down model, in which listeners use the knowledge of topic and previous information about a topic. However, the problem of a foreign language learner is still at the level of phonetics (Brown, 1996).

Likely, to everyone who has learned a language as a foreign or second language is familiar with the difficulty of listening to the target language and unsuccessful trying to have a good and complete communication despite many years of practicing in the target language. Usually, learners know the meaning of the words when they are visible but they do not understand or recognize the words orally. The important reason of this miscommunication is the inability of listeners to distinguish the words spoken form. In addition, listeners likely have good vocabulary knowledge but they cannot be able to use this ability under the pressure of time. There is a familiar phenomenon to learners of a foreign language, that is, what to say and how before or after the conversation but not they are conversing. Additionally, learners might have acceptable knowledge about the vocabulary and 
grammar to make correct sentences in answer to what the speaker has just said but they cannot be able to use their knowledge fast enough (Hulstijn \& Heuven, 2003).

As a comprehension process, listening shares many important characteristics with reading (Bae \& Bachman, 1998; Kintsch, 1998; Samuels, 1987). Both require receptive language processing, which involves decoding and interpretation. Both processes, therefore, use two basic knowledge sources: linguistic knowledge (e.g., vocabulary and syntax) and world knowledge (e.g., topic, text structure, schema, and culture) for purposes of text comprehension. Like reading, listening also entails top-down and bottom-up processing to apply these knowledge sources to the language input during comprehension.

According to Hulstijn and Heuven (2003), attaining the information of a language is a necessary step to using a foreign language fluently, but if it is restricted to knowledge allocation, learners are not able to be fluent users and are never able to be a near-native foreign language speaker. They also cited that understanding the oral language is more than matching the sounds and meanings and it includes four sub-processes of hearing or perception, classification of incoming sounds, word recognition, and comprehension. Additionally, Ellis in Hulstijn and Heuven (2003) stated that the word recognition refers to linguistic knowledge. So, the competence of the structure of the language is needed to the decoding of the syntactic relationship amid the words that make a sentence and are part of the linguistic knowledge of the listener.

The second sub-process of listening skill is the classification of incoming sounds. Speech sounds are different from point of view of phonetic aspects each of which probably depends on many aural cues (Hayward, Rietveld \& van Heuven, as cited in Hulstijn \& Heuven, 2003). The word recognition is the third sub-process of listening skill. In this process, the stream of sounds is separated into linguistic units such as morpheme and words. Then, the meanings are recovered from long term memory (Hulstijn \& Heuven, 2003). Comprehension is the fourth sub-process of listening skill. When the speaker utters groups of sounds, they are classified into grammatical groups; then the relationship of words and meanings is demonstrated: the incoming information gets analyzed. Because of the existence of redundancy in communication, making the exact grammatical analysis to listeners is not necessary; furthermore, they explained that the speed of delivery and the existence of the limitation on the ability of a listener to processing makes it relatively impossible to build grammatical analyses in details. This process depends on the learner's competence. 


\section{Models of Listening}

Traditionally, listening was considered as a passive skill in which the listener gets input which is sent by the interlocutor. Listening was much seen as an active and explanatory function in which the message is produced between speakers and listeners. Context shapes the meanings and the listener constructs it through of explaining (Lynch \& Mendelsohn, as cited in Nation \& Newton, 2009). Additionally, two models of the listening process have been proposed, namely, Bottom-up Process and Top-down Process. The bottom-up process includes collecting the message part by part and from details to the whole by the listener. It contains understanding and analyzing the speech stream to the great extent larger levels starting with all features of languages in a sentence level and context (Field, as cited in Nation \& Newton, 2009). On the other hand, gathering messages from whole to detail by the listener, that is, use pre-information and the related content and context is called top-down process. In this process, listeners use their knowledge about context to understand the message in the conversation, and they use some details of the message to revise and confirm. Note that, when we see these two processes together, we will see as one of the sub-skill. Possibly, the oral message can be understood by taking some keywords and points from context without pay attention to the grammar of the message. Or it can be said; understanding can take place without noticing (Swain, as cited in Nation \& Newton, 2009). Hence, though paying attention to meaning in listening is important, but learners need to focus on details, therefore, listeners need to chances to notice details of a message so they may learn some unimportant details of language which are not essential to communication but are necessary to accuracy. Pay attention to meaning in listening particularly focuses on top-down approach (Nation \& Newton, 2009).

Therefore, Lynch and Mendelsohn (as cited in Nation \& Newton, 2009) explained in recent studies the main role of bottom-up functioning in second language listening. According to Tsui and Fullilove (as cited in Nation \& Newton, 2009), listeners who are good at this skill outperformed from unskilled listeners to reply to the questions in which their answers were not in the content of the message. It means that the unskilled listeners to answer the questions were dependent on the content of the message.

\section{Recent Studies}

Recently, there has been an increasing amount of literature on bilingualism and different skills (e.g. Bialystok \& McBride-Chang, 2005; Calvo \& Bialystok, 2013; Carlo, 2008; Gorjian \& Mahmoudi, 2012; Lambert, 1997; Lee \& Kim, 2011; Legac 
(2007); Merrikhi, 2012; Najafisarem, 2009; Saffarian, Gorjian \& Nejad Fazel, 2013; Samadi \& Maghsoudi, 2013; Siegal, Iozzi \& Surian, 2009; Tafaroji-Yeganeh, 2013; Yamchi \& Kumar, 2016).

Lambert (1997) conducted a study in which the factors of age and socioeconomic status have been controlled; it was found out that bilingualism does not have negative effects on cognition. In addition, they found out that balanced bilinguals were better than others in the forming of concept and mental capabilities.

Legac (2007) explored the listening comprehension in monolingual and bilingual primary school students of English as a foreign language. The participants of both groups had been equally exposed to English. They took a listening comprehension test from the Cambridge Preliminary English Test. The results of the study showed that bilingual students performed significantly better than monolingual students in listening comprehension test. A possible reason for the bilingual advantage was that their experience with two languages would reduce general foreign language anxiety and their listening anxiety in learning a new foreign language.

Gorjian and Mahmoudi (2012) studied the role of bilingualism and monolingualism in listening comprehension of learning English as a foreign language. The important aim of their study was to examine the effect of monolingualism and bilingualism on listening. They conducted an experimental study on two groups of Arab-Persian bilingual students and Persian monolingual students. Different testing instruments and listening comprehension strategies were employed during the development of the study and the results indicated that using those strategies by monolinguals and bilinguals had a positive effect on their listening comprehension. In addition, they found out that bilinguals outperformed the monolinguals in listening comprehension and their strategies which are used.

Samadi and Maghsoudi (2013) in a similar study investigated bilingual versus monolingual learners' reading comprehension ability regarding their interest in reading comprehension topics. They demonstrated that female bilinguals were better than female monolinguals in female based-text and female monolinguals outperformed male monolinguals in female based-texts. In addition, male monolinguals were better than female monolinguals in male based-texts; however, there were not any differences between male and female monolinguals in malefemale based texts.

Tafaroji-Yeganeh (2013) investigated metacognitive listening strategies awareness among bilingual and monolingual Iranian university students learning English as a foreign language. She contended that the metacognitive listening 
strategies among bilinguals are higher than monolinguals in general. She also stated that the degree of metacognitive awareness is affected by the number of languages known by the participants. On the other hand, Shabani and Najafisarem (2009) also investigated the relationship between bi/monolingual students' learning strategies. They found that there isn't any significant difference between two groups in their strategy use.

Saffarian, Gorjian and Nejad Fazel (2013) carried out several investigations into the effects of bilingualism and monolingualism on EFL learners' performance on reading comprehension Tests. They conducted an experimental study between two groups of Arab-Persian bilingual students and Persian monolingual students. Different test instruments were used during the development of the study in which the results demonstrated that using different strategies by bilingual students had an important and positive effect on their reading comprehension. Moreover, between bilingual and monolingual students was not an important difference regarding their acts on reading comprehension.

Merrikhi (2012) studied the effect of bilingualism on Iranian pre-university students' English grammar proficiency. This study conducted among three groups of Iranian pre-university female students: two composed of Azeri-Turkish bilinguals and Armenian bilinguals and the other of Persian monolinguals. Different test instruments were used during the study. She formed three homogeneous groups by using the Nelson test. After two months of training, the subjects were given a post-test. Finally, she demonstrated that bilinguals were certainly better than monolinguals on English Grammar and Armenian bilingual students outperformed Azeri-Turkish bilinguals.

Lee and Kim (2011) also conducted a study in which the effect of individuals' creativity and different extents of bilingualism as a multicultural experience was investigated. Participants were 116 Korean American students (49 boys \& 65 girls). They found that there was a meaningful relationship between individuals' creativity and different extent of bilingualism, disregarding gender or age. Students who were high balanced bilinguals were more creative. Additionally, girls were better than boys in the fields of bilingualism, illustration, and abstractness of titles; however, age did not affect creativity and bilingualism.

A recent study by Carlo (2008) investigated the effects of bilingualism on speech recognition performance in noise. In this study the bilingualism effects on speech recognition examined. Participants were young Spanish-English bilinguals who had the normal-hearing ability. The ratio of correct speech recognition achieved from bilingual listeners was contrasted to young English and Spanish 
monolingual listeners who had the normal-hearing ability. He found out that the Spanish-English bilingual learners did not outperform the English monolingual learners in speech recognition, but bilingual learners were equal to Spanish monolingual learners.

In 2009, Siegal, Iozzi, and Surian studied the relation between bilingualism and conversational understanding in young children. The major purpose of this study was to investigate whether bilingualism has a positive effect on conversational comprehension in young children. The population of participants was 163 young children whose age was 3-6 years old. Conversational Violations Test was given to participants to indicate their capability to recognize answers of the questions as violations of Gricean maxims of conversation to be educational and avoid repetition, talk the truth and to the point and polite. Although relatively differed in their second language vocabulary, Italian and Slovenian bilingual children commonly were better than Italian or Slovenian monolingual children. Therefore, it was concluded that bilingualism can have a positive effect on communicative responses.

To determine the effects of bilingualism and socioeconomic status on language ability and executive functioning, Calvo and Bialystok (2014) investigated a study in which one hundred and seventy-five children whose ages were 6-years old. They were selected to one of four groups that were different from aspects of socioeconomic status (SES; working class or middle class) and to be monolingual or bilingual. Different instruments such as nonverbal intelligence, language vocabulary tests to assess vocabulary and attention according to picture naming and two executive functioning tests were used. All participants were identical to the basic intelligence tests. But the results of the language and executive functioning tasks were affected by both socioeconomic status and bilingualism. Children who were in Middle-class were better in working-class children on all measures, and bilingual children did not outperform the monolingual children on language tests. Conversely, bilingual children outperformed the monolingual children on the executive functioning tasks. There were no relations between group factors and task factors. Therefore, they proved that bilingualism and socioeconomic status companied particularly and separately to children's advancement without regarding the level of the children on the other factor.

In 2016, Yamchi and Kumar studied monolingual and bilingual differences through which they scrutinized Iranian monolingual and bilingual EFL understudies' tuning in perception of the Latinized Persian subtitling of English films. One listening cognizance test which depended on the phonetic data of the film was regulated to the two gatherings of monolinguals and bilinguals. The 
results indicated that monolinguals outperformed bilinguals on quick phonetic perception of the film.

Therefore, this study will attempt to bridge the gap regarding bilingualism effectiveness on listening comprehension among Azeri Turkish-Persian bilinguals and an attempt was made to compare the results with the other studies conducted on bilingualism phenomenon. In this regard, the method, instruments, and participants of this study in the following sections are presented.

\section{Participants}

The participants in the present study were 44 junior high school students studying in Ramian and Azadshahr high schools in Golestan Province in Iran. All junior high school students were given a biographical questionnaire and based on answers of the questionnaire, 15 bilingual (Azeri-Persian) students and 29 monolingual (Persian) students were selected. The students were females ranging in age from 14 to 15 years old. Persian and Azeri-Turkish were the mother tongue of the participants. According to the results of the Nelson proficiency elementary test, the students' scores were between 14 to 17 out of 30 . So it could be concluded that they were homogeneous. The researcher assigned both classes as the experimental group in Ramian and in Azadshahr. There were 29 monolingual students in Azadshahr class and 15 bilingual students in Ramiyan class.

\section{Materials / Instruments}

Nelson English Language Proficiency Test

The first instrument used in the present study was a Nelson proficiency test to determine the elementary students' level of language proficiency. We chose this level in order to have a homogeneous group that is potentially ready to be instructed the listening skill. Thirty items of Nelson elementary proficiency test were applied to determine the homogeneity of the groups regarding their levels of proficiency as an elementary level student. The rationale behind adopting this test was that it is one of the available standardized tests that can be employed on different levels of students.

\section{Listening Pre/Post Tests}

The second instrument employed in the present study was a listening test which included 30 items in three parts. Listening and comprehension were the 
main test formats employed in the listening tests. The pre-test and post-test were identical and have taken from Basic Tactics Listening book (Richards, 2010). The test score in the pre-test and post-test ranged from 0 to 30. In addition, to check the reliability of the listening scale, the internal consistency reliability of listening was checked by calculating Cronbach's alpha coefficient and it was found that the reliability of listening pre-test and post-test was 0.84

\section{Instructional Material}

The third instrument employed in this study was the listening text which was included in a basic level textbook of the Tactics for listening series (by Jack C. Richards, 2010). It was intended for students who have studied English previously but need further practice in understanding simple conversational language. Each unit features a topic that is related to everyday life such as food, greetings and socializing, or travel. A wide variety of stimulating and useful activities are included to give students graded practice in listening. In addition, listening comprehension tasks are practiced throughout the text. These tasks include listening for keywords, details, gist, making inferences, listening for attitudes, listening to questions and responding, recognizing, and identifying information. The textbook consists of twenty-four units each of which includes five sections. The topic of each unit and key vocabularies for the listening tasks are introduced in the first section. The next three sections include Listening 1, Listening 2, and Listening 3 that are linked with conversations or monologues on the audio program. Moreover, the listening sections provide task-based and graded listening practice. Finally, Conversation Corner as the last section persuades students to move from receptive to productive use of language through structured pronunciation, dictation, and conversation practice. In the present study, just first eight units of the textbook were employed to teach students in both experimental groups.

\section{Biographical Questionnaire}

The fourth instrument employed in the present study was a biographical questionnaire including 5 questions. The items such as father's mother tongue, mother's mother tongue, the communicational language of parents at home, communicational language of the participant with parents at home, participants' level of familiarity in Azeri-Turkish, and the level of understanding in AzeriTurkish language were asked. It was given to all junior high school students to select monolingual and bilingual students. 


\section{Procedure}

At first, the biographical questionnaire was given to all junior high school students to select the bilingual and monolingual groups to conduct the study. In the present study, both bilingual and monolingual groups were assigned as experimental. One class included 29 monolingual students and the other 15 bilingual students. Secondly, to control the students' level of proficiency, they were given a 30-item elementary Nelson proficiency test. The participants were required to answer the questions in 30 minutes. Thirdly, both groups received listening pretests to measure their listening skill before the treatment. The pre-test also included 30 items that the participants were asked to answer in 30 minutes. Then, both groups were given the handouts of the first eight units with the audio files. The content of the treatment was identical for two groups. In each session, the students were required to listen to each unit before the class. Both groups received eight units of Basic Tactics as listening textbook for eight weeks, two sessions in a week, and a total of 16 sessions. Each session lasted 30 to 45 minutes considering the length of the units. In each unit, five sections were covered: Getting ready, three listening sections in which were employed two tasks in each section, and $a$ conversation corner. Additionally, at the beginning of each session, the unit's vocabulary was pre-taught and the title of the units was introduced.

Next, the directions of the first section were read and activities were answered either individually or in pairs by participants and the students' answers were checked by the teacher. Then, the audio file of the first listening test was played and activities were tried to be done by participants. Then, the rest of the audio files of listening passages, listening 2 and 3 were played with the same procedure.

To familiarize students with basic intonations, stress patterns reductions which is commonly employed by native speakers of English to improve students' listening comprehension skills. Two tasks in each unit focuses the students' attention on the pronunciation points and they were continued until all students could distinguish sounds correctly. In addition, to improve the students' discrete listening skills and reinforce their understanding of pronunciation two dictation tasks were given to them in which the students pre-read the dictation activity and were asked questions to identify key details of the conversation. Then, the audio passage was played and students listened to the whole conversation without filling in the dictation blanks. Finally, both groups received a listening post-test. 


\section{Design of the Study}

Most of the time, second language researchers are not able to find participants randomly in selected groups and they have to work with intact groups. According to Brown and Rodgers (2004), it is not easy to conduct studies in the field of education with real students and real teachers which are pure experimental studies. Hence, most of the studies tend to be quasi-experimental rather than real experimental studies. Therefore, this study was designed as a quasi-experimental study to focus on the effect of bilingualism on EFL learners' listening comprehension. There are two variables in this study, one independent variable, and one dependent variable. In this study, bilingual and monolingual have been considered as two independent variables. Listening skill was the dependent variable. The researcher had no control over the selection of the participants; they were conveniently selected as they were in classes of high schools in both Azadshahr and Ramian cities.

\section{Results}

\section{Reliability of the listening scale}

To check the reliability of the listening scale, the internal consistency reliability of listening was checked by calculating Cronbach's alpha coefficient and, as it is presented in table 1 , it was found that the reliability of listening pre-test and posttest was 0.84 .

Table 1.

Reliability of Pre-test and Post-test

\begin{tabular}{clcccc}
\hline & & N & $\%$ & Cronbach's Alpha & $\begin{array}{l}\text { N of } \\
\text { Items }\end{array}$ \\
\hline \multirow{3}{*}{ Cases } & & & & & \\
& Valid & 44 & 100.0 & & 60 \\
& Excluded & 0 & .0 & .849 & \\
& Total & 44 & 100.0 & & \\
\hline
\end{tabular}

\section{Testing the Research Question}

The research question was to examine whether there is a meaningful difference between Azeri-Persian bilinguals and Persian monolinguals in their listening 
comprehension or not. The descriptive statistics for the listening pre-test and posttest in both experimental groups are detailed in Table 2. As observed, the mean score of monolingual and bilingual participants in the pretest were respectively 11.66 and 13.60, while the mean score of monolingual and bilingual participants in the posttest were 19.69 and 19.87 respectively.

\section{Table 2.}

\section{Descriptive Statistics for Listening Pretest and Posttest}

\begin{tabular}{lllccc}
\hline & Language & $\mathrm{N}$ & Mean & Std. Deviation & Std. Error Mean \\
\hline \multirow{2}{*}{ PRE total } & Monolingual & 29 & 11.66 & 5.499 & 1.021 \\
& Bilingual & 15 & 13.60 & 4.718 & 1.218 \\
& & & & & \\
POST total & Monolingual & 29 & 19.69 & 4.335 & .805 \\
& Bilingual & 15 & 19.87 & 3.623 & .935 \\
\hline
\end{tabular}

However, a comparison of the means of pre and posttest of both experimental groups demonstrated a gain score of 6.27 (19.87 - 13.60) for bilingual and a gain score of $8.03(19.69$ - 11.66) for the monolingual group. This indicates the development of the listening comprehension of both groups. Furthermore, the initial look at the mean differences between bilingual and monolingual groups indicates that the monolingual group outperformed the bilingual group.

The standard deviation shows the dispersion of scores from each other, the more similar the scores are to each other, the lower the measure of dispersion will be. The standard deviations of post-test scores in bilingual and monolingual and group are 3.62 and 4.33, respectively. While in the pre-test of the bilingual and monolingual groups, they are 4.71 and 5.49, respectively. This shows that the dispersion of posttest scores is less than that of pretest scores in both groups.

Standard error mean shows how close the sample mean is to the population mean. The standard errors of post-test scores in the bilingual and monolingual groups are 0.93 and 0.80 , respectively. While in the pre-test of the bilingual and monolingual groups, they are 1.21 and 1.02, respectively. This shows that the error mean of post-test scores is decreased in both groups and shows the improvements of the participants in both groups in the post-test. 
Table .3.

Independent Samples Test of Listening Pre-test and Post-test

\begin{tabular}{|c|c|c|c|c|c|c|c|c|c|}
\hline & \multicolumn{5}{|c|}{ Levene's Test for Equality of Variances } & \multicolumn{4}{|c|}{ t-test for Equality of Means } \\
\hline & \multirow[t]{2}{*}{$\mathrm{F}$} & \multirow[t]{2}{*}{ Sig. } & \multirow[t]{2}{*}{$\mathrm{T}$} & \multirow[t]{2}{*}{ Df } & \multirow[t]{2}{*}{ Sig. (2-tailed) } & \multirow[t]{2}{*}{$\begin{array}{l}\text { Mean } \\
\text { Difference }\end{array}$} & \multirow[t]{2}{*}{$\begin{array}{l}\text { Std. Error } \\
\text { Difference }\end{array}$} & \multicolumn{2}{|c|}{$\begin{array}{l}95 \% \text { Confidence } \\
\text { Interval of the } \\
\text { Difference }\end{array}$} \\
\hline & & & & & & & & Lower & Upper \\
\hline Pre-test & 2.107 & .154 & $\begin{array}{l}- \\
1.16\end{array}$ & 42 & .251 & -1.945 & 1.670 & -5.315 & 1.426 \\
\hline Post-test & 2.234 & .142 & -.13 & 42 & .893 & -.177 & 1.308 & -2.816 & 2.462 \\
\hline
\end{tabular}

In the next step, to check whether these mean differences from pre- to post-tests are significant, inferential statistics were employed. An independent t-test was conducted to determine whether any significant difference might be observed for the listening pre-test of both groups. The results of the independent t-test, as presented in Table 3, indicate that there is not any significant difference between bilingual and monolingual groups' scores on the listening pretest $(\mathrm{t}(42)=-1.16, \mathrm{P}=.25>.05)$.

In addition, the results of the independent t-test, as depicted in Table 3, indicate that there is not any significant difference between bilingual and monolingual groups' mean scores on the listening posttest $(\mathrm{t}(42)=-.13, \mathrm{P}=.89>.05)$.

\section{Discussion}

The purpose of the present study was to examine the effect of bilingualism on EFL learners' listening comprehension. The research question asked whether bilingualism affected EFL learners' listening skill or not. To test the research question the data was calculated by descriptive statistics and independent samples t-test for pre and post-tests. An initial look at the descriptive statistics revealed that the mean of listening comprehension in the post-test was higher than the pretest in both experimental groups. However, the results of the analysis showed that there is no significant difference in listening post-test in both experimental groups.

Thus, it can be concluded that bilingualism did not have any significant effect on elementary learners' listening skill. 
Through analysis of the data, no considerable effect of bilingualism on listening comprehension among Azeri-Persian bilinguals was found. The results of the present study do not support the related studies finding a positive effect of bilingualism on learning (e.g., Calvo \& Bialystok, 2013; Lee \& Kim, 2011; Merrikhi, 2012; Samadi \& Maghsoudi, 2013; Siegal, Lozzi \& Surian, 2009).

This finding is also inconsistent with the findings of Yamchi and Kumar (2016) who found that monolinguals outperformed bilinguals on quick phonetic perception of the films and Gorjian and Mahmoudi (2012) who found that there was a significant difference between the performance of bilinguals and monolinguals regarding their performances on listening comprehension and reported the positive effect of bilingualism on listening comprehension in ArabPersian bilingual students and stated that bilingualism may have a positive effect on better comprehending of English tasks because of the experiences in listening to the different sounds in two Arab and Persian languages. And, they also stated that the similar phonemes in both Arabic and English languages (e.g., $/ w /, / \theta /$, etc.) y have possibly direct mutual effect on one another as they can recognize different sounds and symbols interactions, but those reasons cannot confirm in process of listening comprehension improvement of Azeri-Persian bilinguals. However, more research is needed to examine the effect of bilingualism in EFL Learners.

So, the reasons for the present finding might include some unsystematic errors which were unobservable in some students such as tiredness and reluctance. Another evidence for such a result is that the teacher might not be enough proficient enough to correct and analyze the problematic area of the students. Additionally, the limitation of the time may affect the listening comprehension of the students. If the study time had been longer, the results might have been different. Furthermore, existence of some phonemes (e.g., /w/, / $\theta /, / \partial /, / \mathrm{r} /, / \mathrm{t} /$, $/ æ /$, etc.) on Azeri-Turkish that exist similar phonemes (e.g., /v/, /t/, /d/, /r/, /e/) respectively on Persian language may have negative effect on English listening comprehension. The last reason seems to be due to the level of the participants, elementary, who may not enough knowledge to recognize the English sounds and to have perfect comprehension.

\section{Conclusions}

In the present study, an attempt was made to investigate the role of bilingualism on learners' listening comprehension in Azeri-Turkish vs. Persian elementary female students. The improvements in listening comprehension were 
evidenced in the practical use of a listening comprehension task during the treatment. Data collected from the participants' performance in both pre-test and post-test showed considerable progress in listening comprehension during an 8week treatment. The present study just involved elementary level students therefore the results cannot be generalized to all levels to indicate whether there will be any significant effect of bilingualism on higher-level students. Furthermore, it cannot be generalized to children who cannot read or write in English. In addition, it cannot be generalized to all kinds of bilinguals, because this study just conducted in Azeri-Turkish vs. Persian students. Even though, previous studies explored that bilingualism has a positive effect on learning (e.g., Calvo \& Bialystok, 2013; Gorjian and Mahmoudi, 2012; Lee \& Kim, 2011; Merrikhi, 2012; Siegal, Lozzi \& Surian, 2009; Samadi \& Maghsoudi, 2013), but may depend on unknown factors and the bilinguals' native tongue. Similarity or differences of sounds and phonemes of the native tongue of participants may have a positive or negative effect on listening comprehension.

The findings of this study suggest that bilingualism phenomenon may have a positive effect on the participants' performance in listening comprehension pre-test (see table 2), but during treatment may intervene other factors such as fatigue, unwillingness and novice teacher may have no positive effect and alter the influence of the bilingualism on listening comprehension in the case of this study. However, the results of the present study reveal that bilingualism did not affect junior female students' listening comprehension.

\section{Pedagogical Implications and Suggestions for Further Research}

Several pedagogical implications for second language and EFL learners, teachers, policymakers, and the book designers can be derived: 1 . The present study conducted on the effect of bilingualism on EFL learners' listening skill revealed that if teachers employ specific strategies, tasks of listening skill, bottom-up process, and two-way listening in the classroom, participants' listening comprehension will improve. 2. The present study is conducted in private and state schools respectively in Azadshahr and Ramian in Iran. Concerning state and private educational systems in the Iranian context, it can be found out that novice teachers, textbooks, and limitation of time of the English classes during a week and materials may negatively affect the EFL learners. The policymakers should provide a suitable educational schedule about focusing on teaching listening skill as a prior skill in both state and private educational systems. 3. It provides language teachers with information about listening comprehension with Iranian students at the 
elementary level. Language teachers might be encouraged to try out the different strategies and processes of listening comprehension such as top-down, up-down, one-way, and two-way listening in the classroom. 4. It indicates that teachers can motivate learners to give the chance to students to participate in listening comprehension activities. It will give them a good chance to challenge themselves and they are motivated. 5. This study may give more information about listening skill to the text-book writers and designers of skills textbooks to design some more listening tasks in junior high school English books in Iran. 6. The results of this study give information about the kinds of listening comprehension, listening activities, and listening strategies to students.

The findings of the present study suggest further study in future research efforts: 1 . The number of the participants in this research was limited hence the results cannot be generalized to other learners with other bilinguals. In the future study, it may be conducted with more numbers of participants among bilinguals with other languages. 2. The present study is conducted among junior high school female students. In order to generalize the finding of this study considerably more work will be needed to replicate this research on the junior high school male students with different levels of students. 3. The present investigation was limited by a short period, for future research it can be done about more factors in the language area, to more deeply investigate how bilingualism may influence listening comprehension, in this way the researcher should spend more time. 4 . The present study is conducted among Azeri-Turkish vs. Persian junior high school female students. Conduct of the study in the case of other dialects in Iran such as Turkman-Persian and Baloochi-Persian would help us to establish a greater degree of accuracy on this matter. 5. To more clarify the effect of bilingualism on language learning, it is also advisable to conduct the same study on the other skills of the English language such as writing, reading, speaking, and grammar. 6. The present research was not specifically designed to evaluate factors related to sounds and phonemes of bilingual students' native language and its effect on listening comprehension, future research should, therefore, concentrate on the investigation of the effect of sounds and phonemes of bilingual students' native language and in this case, they will be similar to or different from English phonemes.

\section{Disclosure statement}

No potential conflicts of interest were reported by the authors. 


\section{References and notes:}

Bae, J., \& Bachman, L. (1998). A latent variable approach to listening and reading: Testing factorial invariance across two groups of children in the Korean/English two-way immersion program. Language Testing, 15, 380-414.

Bhatia, T. K., \& Ritchi, W. C. (2006). The Handbook of Bilingualism. United Kingdom: Blackwell Publishing.

Bialystok, E. (2003). Bilingualism in development: Language, literacy, and cognition.New York: Cambridge. University Press.

Bialystok, E., \& Chang, C. M. (2005). Bilingualism, Language Proficiency, and Learning to Read in Two Writing Systems. Educational Psychology, 97(4), 580-590.

Brown, G. (1996). Listening to spoken English. New York: Longman Inc.

Calvo, A., \& Bialystok, E. (2014). Independent effects of bilingualism and socioeconomic status on language ability and executive functioning. Cognition, 130(3), 278- 288.

Carlo, M. A. (2008). Effects of bilingualism on speech recognition performance in noise. (Doctoral dissertation, University of South Florida). Retrieved April 11, 2008 from http://scholarcommons.usf.edu/etd/162.

Crystal, D. (1987). The Cambridge encyclopedia of language. Cambridge: Cambridge University Press.

Ellis, N. (2005). Introduction to acquisition. In J. E. Kroll, \& A. M. DE Groot (EDs.), Handbook of bilingualism (pp. 3-8). New York, Oxford university press.

Gorjian, B., \& Mahmoudi, K. (2012). The role of bilingualism and monolingualism In listening comprehension of learning English as a foreign language. Asian Social Science (ASS), $1(4), 313-317$.

Graham, S. (2006). Listening comprehension: The learners' perspective. System, 34, 165-182. http://dx.doi.org/10.1016/j.system.2005.11.001

Guagnano, D. (2009). Bilingualism and cognitive development: A study on the acquisition of number skills. Unpublished doctoral thesis, Università degli Studi di Trento.

Hamers, J. F., \& Blanc, M. H. A. (2004). Bilinguality and bilingualism. United Kingdom: Cambridge University Press.

Heredia, R. R., \& Altarriba, J. (Eds.). (2013). Foundations of bilingual memory. New York: Springer.

Hulstijn, J., \& Heuven, V. V. (2003). Developing second-language listening comprehension: Effects of training lower-order skills versus higher-order strategy. (Doctoral dissertation, University of Van Amsterdam).Retrieved Jun 10, 2003 from http:/ / wwwlot.let.uu.nl/.

Lambert, W. (1997). Culture and language as factors in learning and education. In F.

Eckam (Ed.), Current themes in linguistics and language typologies (pp. 15-30). Wahington, DC: Hemisphere Publishing.

Lee, H., \& Kim, K. H. (2011). Can speaking more languages enhance your creativity? Relationship between bilingualism and creative potential among Korean American students with multicultural link. Cognition, 50(8), 1186-1190.

Legac, V. (2007). Foreign-language anxiety and listening skill in Croatian monolingual and bilingual students of EFL. In J. Horvath, \& M. Nikolov (Eds.), UPRT 2007: Empirical studies in English applied linguistics (pp. 217-243). Pécs: Lingua Csoport.

Merrikhi, P. (2012). The Effect of Bilingualism on Iranian pre-university students' English grammar proficiency. Theory and Practice in Language Studies, 2(2), 360-370.

Nation, I. S. P., \& Newton, J. (2009). Teaching ESL/EFL listening and speaking New York and London: Routledge.

Oxford, R. (1993). Research update on L2 listening. System, 21, 205-211. http://dx.doi.org/10.1016/0346-251X(93)90042-F

Paradis, M. (2005). A neurolinguistic theory of bilingualism. Amsterdam: John Benjamins.

Pavlenko, A. (2005). New approaches to concepts in bilingual memory (summary). Bilingualism: Language and Cognition, 3(1), 1-4

Richards, J. C., \& Schmidt, R. (2010). Longman dictionary of language teaching and applied linguistics(Ed.). London: Longman. 
Saffarian, R., Gorjian, B., \& Nejad Fazel, A. (2013). Effects of Bilingualism and Monolingualism on EFL Learners' Performance on Reading Comprehension Test. Asian Social Science (ASS), 4(2), 820-823.

Samadi, F., \& Maghsoudi, M. (2013). Bilingual versus monolingual learners' reading comprehension ability reading their interest in reading comprehension topics. Natural and Social Sciences, 2(2), 23-34.

Saunders, G. (1988). Bilingual children: From birth to teens (pp. 2-3). Philadelphia: Short Run Press.

Schroeder, S. R., \& Marian, V. (2012). A bilingual advantage for episodic memory in older adults. Journal of Cognitive Psychology, 24(5), 591-601. http://dx.doi.org/10.1080/20445911.2012.669367

Shabani, M.B., \& Najafi-sarem, S. (2009). The study of learning strategies Used by male/ female monolingual and bilingual speakers as EFL learners. Unpublished MA thesis, University of Ilam: Iran.

Siegal, M., Lozzi, L., \& Surian, L. (2009). Bilingualism and conversational understanding in young children. Cognition, 110(1), 115-122.

Tafaroji-Yeganeh, M. (2013). Metacognitive listening strategies awareness in monolingual versus bilingual EFL learner. Procedia - Social and Behavioral Sciences, 70, 1787 - 1793. 